\title{
Coaching practitioner development: Beyond training and supervision to growth focused therapy
}

\author{
Travis Kemp \\ UniSA Business School \\ University of South Australia \\ Adelaide, Australia
}

\begin{abstract}
Coaching is one of the youngest of the 'helping' disciplines. As such, its practice is informed heavily by the extensive body of knowledge that encompasses the psychological, social, and behavioural sciences (Crowe, 2017). As our understanding of coaching practice deepens, and the coaching client population grows in its sophistication, coaching practitioners are being challenged to extend the depth of their theoretical knowledge, technical competency, and standards of professional practice. In response to this challenge, training and educational programs have advanced rapidly in the last decade. Multiple post-graduate coaching programs now exist globally, and several professional associations representing coaches have adopted many of the practice standards and requirements mandated by the Psychology profession. However, as the demands on coaching practitioners continue to grow, and the application of coaching as a method and process broadens to more complex contexts and situations, coaching practitioners must continue to extend their personal growth and development beyond simply their skills and knowledge. The current discussion explores the coach as 'helper' and the importance of coaching practitioners' movement towards purposefully and deliberately engaging in deeply introspective personal growth and development. Further, this discourse seeks to establish a compelling proposition for coaches to consider extending their development into the personal therapeutic realm. Specifically, this discussion will consider Growth Focused Therapy for coaching practitioners as a progressive and logical 'next step' in their personal development and practice journey.
\end{abstract}

Keywords: coach development; therapy; supervision; professional practice; growth focused therapy

\section{Introduction}

As the body of knowledge informing Coaching Psychology continues to expand, the need to broaden our enquiry beyond simply the methods, models 
and approaches utilised in coaching becomes self-evident. In acknowledging the positive and applied foundations of coaching, our focus to date on deepening our understanding of the practice of coaching and the phenomenological context in which coaching occurs, has made a valuable contribution to the field's development. Of equal importance though is building a parallel and commensurate understanding of the coaching practitioner herself. The current discourse argues that developing a deep, intimate and accurate understanding of 'self' as a coaching practitioner is a foundational platform on which impactful and developmentally efficacious coaching interventions are enabled.

The criticality of the coaching alliance has been identified previously (Kemp, 2008 \& 2009; O'Broin \& Palmer, 2009; O’Broin \& Palmer, 2010) however the challenge for coaching practitioners is to progressively deepen our ability to introspect, explore and understand our own unique psychological, behavioural, affective and cognitive constructs in order to effectively and accurately manage ourselves and hence optimise our ability to facilitate our clients' growth and development intentions and aspirations.

In support of this intent, this paper will illuminate the coach as 'helper' and compare and contrast the similarities and differences in coaching practice with allied helping disciplines and professions. The challenges of defining our scope of practice as coaches will be addressed and the subsequent requirements for the preparation and maintenance of professional practice competencies and standards for coaches will be explored. The importance of the practitioner's role as a developmental 'instrument' in supporting client learning will be presented and their ability to 'calibrate' accurately being vital to delivering efficacious client outcomes will be established.

The discourse will conclude with a proposition; a 'call to action' if you will, for coaching practitioners to consider in support of their personal and professional development. Drawing on an extensive evidence base from the allied helping professions, Growth-Focused Therapy will be presented and explored with guidelines and recommendations for practitioners to consider in pursuing an advanced form of coaching practitioner development.

\section{The pathway to practice for coaches to date}

The constraints of the current discussion preclude an extensive historical account of the development of the coaching industry. Suffice to say, coaches have come to be viewed as the practitioners of a method, framework and 
process of human learning, growth, and development intervention we now define as coaching. It is, however, critical to establishing an accurate understanding of the broader situational context for the development of coaching practitioners. Contrary to an extensive and growing assertion from within the coaching industry, coaching is increasingly being delivered by professional practitioners (those paid to provide services) but it is not a profession within the universally accepted and acknowledged definition of that term (Goode, 1960). In addition, it does not meet the legislative, structural, governance or public accountability requirements that are characteristic of professions. Specifically, the structure and function of the coaching industry fails to meet specific core criteria. First, coaching practice is not restricted to those individuals who are legally licensed or registered to provide coaching services. Second, there are no universally accepted statutes, training standards, practice methods, validated models or unique tools that clearly define coaching as a unique profession. Third, there are no barriers to practice entry or legislated standards that constrain and govern practice.

Simply stated, anyone who wants to coach, can coach. There are no barriers or restrictions that exist that prevent an individual from promoting herself as a coach. Despite this conundrum, the coaching industry continues to raise its self-imposed standards and professional coaches continue to improve their helping skills, knowledge and understanding of the coaching process. Consequently, as the practice of coaching continues to develop and diversify, practitioners are increasingly compelled to raise their standards of professionalism and practice within a complex, self-regulating industry. As coaching practice 'professionalises' itself, it is inevitable that the coaching industry and practitioner community will seek to establish progressively higher benchmarks and standards of practice and in doing so, will hold their colleagues and providers to progressively higher standards.

\section{Refining the scope of practice of coaching practitioners}

Contrary to the misleading rhetoric perpetuated by some commentators and representative organisations from within the coaching industry, coaching, counselling and psychotherapy are far from discreet disciplines, nor are they clearly differentiated helping processes or methods delineated by robust evidence-based boundaries. Nevertheless, this misinformation continues to be perpetuated. 
"The main distinctions between coaching and psychotherapy are based on focus, purpose, and populations. Coaching focuses on visioning, success, the present, and moving into the future. Therapy emphasizes psychopathology, emotions, and the past in order to understand the present. The purpose of coaching is frequently about performance improvement, learning, or development in some area of life while therapy often dives into deep-seated emotional issues to work on personal healing or trauma recovery. Coaching tends to work with well-functioning individuals whereas therapy work tends to be for individuals with some level of dysfunction or disorder. Therapy works more with developing skills for managing emotions or past issues than coaching."

(Hullinger \& DiGirolamo, 2018, p.6)

Unfortunately, these assertions continue to foster confusion, where, as Spinelli (2010) succinctly points out, none should exist;

“...it is a huge error to view therapy as being predominantly pastoriented. More correctly, I believe therapy is concerned with the living or presenting past, and, as such, is more attuned to the present than coaches usually understand it to be." (p. 53).

Indeed, the key assertions made by many coaches of what coaching and therapy are or are not are neither factually accurate nor helpful to the advancement of coaching practice and the development of coaching practitioners. Developmental coaching, for example, focuses on the longer term needs and aspirations of clients rather than short term, performance-related goals and behaviours (Bachkirova, 2007). Likewise, psychotherapy and counselling concern themselves with a widely diverse range of complex and integrative facets that focus on optimising health, well-being and performance (Grohol, 2020) rather than simply focusing on "psychopathology, emotions and the past...".

These similarities are particularly important in considering current population mental health data. For example, currently in Australia at least one in three women and one in five men are likely to experience significant anxiety in their lifetime (Australian Bureau of Statistics, 2018) and 35\% of employees state they would not want anyone to know about their experience of depression or anxiety (TNS, 2014). A simple probability analysis yields evidence of a high probability that coaches at some point in their practice, will find themselves working with clients who are not "well-functioning". Indeed, in a study 
examining the mental health of executive leaders presenting for coaching, Kemp and Green (2010) reported that 39\% of males and 36\% of females met the criteria for mental health 'caseness' or concern on a standardised mental health screening instrument. This finding again calls into question the assertion that leaders who seek out coaching are psychologically well. It is imperative that coaching practitioners recognise that non-clinical populations also contain vulnerable clients (Whybrow \& Palmer, 2006) and that this does not, nor should it, automatically preclude them from coaching. Indeed, some mental health professionals from the field of Psychiatry have suggested that coaching may provide an integral and valuable function in patients' mental health recovery (Bora, Leaning, Moores and Roberts, 2010).

Instead of continuing to perpetuate this misleading and inaccurate rhetoric, we must instead recognise, acknowledge and educate the coaching industry, representative bodies and professional practitioners that mental health and well-being is better understood as a complex variable that is situationally influenced and humans' general state of mental health moves along a dynamic continuum. This continuum can be seen to be anchored at its extremes by 'floundering' at one end and 'flourishing' at the other.

As we have touched upon earlier, coaches, like Psychologists, fall firmly within the broad category of 'helpers'. Indeed, when examining the characteristics that Egan and Reese (2019) outline as critical to becoming an effective therapist, these also apply equally to what is required of an effective coach. As coaching practitioners, we must better equip ourselves to recognise where on the mental health continuum our clients are operating, and subsequently, what knowledge, skills and experience are required to engage effectively and responsibly with them at that point on the continuum. This will be dependent upon our own level of self-understanding and awareness as much as the ability to recognise when additional and specialised practitioners, such as a Psychologist, is required to assist a client. Perhaps even more importantly however is the coach's ability to develop an acute understanding of her unique limitations and broader ethical responsibilities when working with clients at differing points on this continuum. As professional human helpers, the importance of raising our personal knowledge and competency in order to responsibly work with complex clients is vital to the continuing professionalisation of coaching practice and for the psychological safety and welfare of our most vulnerable clients, who may also appear deceptively high functioning, productive and 'balanced'. 


\section{Supervision: An important foundation for introspection and reflective coaching practice}

Considerable research effort has focused on developing our understanding of the 'what' and 'how' of coaching practice in order to guide the training and practice of coaches. Specifically, many researchers have dutifully attended to observing the interactions and conversations that occur between 'coach' and 'coachee' when coaching is happening. What do coaches do in the coaching session? What do they say and how do they say it? What do coachees do in response to what their coachees say and how do they change their behaviour, thinking and perceptions associated with their context and intentions? It is this last question that highlights the rich introspective laboratory that professional supervision provides for coaches and makes it an invaluable discipline for coaching practitioners to engage with.

Despite the obvious richness and potential of supervision though, there remains little consensual agreement on its definition, purpose, structure or function within a coaching-specific context, nor on the issue of whether supervision should be compulsory for coaches (Gray, 2007, 2017; Moyes, 2009; Grant, 2012). Furthermore, the value that supervision provides coaching clients themselves regarding the quality of coaching delivery and standards of coaching appear to be tangential at best (Lawrence \& Whyte, 2013).

Whilst continuous supervision is a requirement of many registered health professions and is mandated by the statutory bodies regulating the practice of these professions, Bernard and Goodyear (2009) suggest that supervision is determined by the purpose it serves, the participants involved, and the context or place in which it occurs making it highly variable in regards to its structure, function and outcomes.

Whilst there have been extensive and valuable efforts to explore, illuminate and define coaching supervision specifically (Bachkirova, Jackson \& Clutterbuck, 2011; Hawkins, 2006) there remains continuing debate as to the methods, approaches, frameworks and contexts that elicit the most value for coaches. Further, insights and understanding regarding the impact and value of participating in supervision for the coaching client remains complex and elusive. Attempts to develop a deeper understanding of the structure and function of coaching supervision within specific coaching domains, such as that presented by Joseph (2016), whilst valuable and insightful, raise further challenging questions as to whether or not supervision within specific coaching practice domains may require specific supervision methods or approaches. 
Despite this ambiguity, coaching supervision in some form or another, appears to be of perceived value to many practitioners and provides an opportunity for critical peer review, consultation, critique and reflection on the approaches and practices employed by coaches. Importantly, it provides coaches with an insight into the value of personal introspection and in the adoption of a mindset of openness, vulnerability and personal courage; behaviours that we seek to model in our coaching relationships with clients.

Whilst these benefits alone justify the collective importance placed on professional supervision, it also provides the rich source of content, experience and perspective that is invaluable when considering embarking upon an introspectively focused development experience such as personal psychotherapy.

\section{Growth focused therapy: Extending our capabilities as coaching practitioners}

The widely held view of psychotherapy being a treatment for mental illness continues to persist in contemporary society. As such, the suggestion that one might consider engaging in psychotherapy often elicits offence, denial, and defensiveness. However, as we will discover, whilst psychotherapy has established a strong evidence base supporting its efficacy in treating mental illness, the absence of psychotherapy's preventative, mental health maintenance and personal development efficacy is equally well supported (Egan \& Reese, 2019) but frustratingly overlooked.

Further, the current author has outlined previously (see Kemp, 2008) the many cognitive biases that necessitate deep personal exploration by the coaching practitioner. Beyond these primary biases, Kilburg (2004) highlighted the ways in which a coach's subconscious dynamic materially impacts on the structure and functioning of the coaching alliance through a range of psychodynamic phenomenon including transference, countertransference and projection. Similarly, Kets de Vries (2006) highlighted the many broader complexities associated with psychodynamic considerations as they relate to coaching leaders. It is vital therefore that coaches develop their ability to identify, observe, monitor and adjust their cognitive-behavioural position, both synchronously and asynchronously, when engaging with their clients. This process is best conceptualised metaphorically as a 'calibration' similar to that which would be applied to the validation of any gauge or measurement device. In this context, if the coach is an 'instrument for change', the perennial developmental focus for coaches becomes; Am I an accurate instrument for my 
client? Coach calibration therefore becomes a continuing process of ensuring my biases, strengths, weaknesses, beliefs, and experiences are identified, understood, corrected and managed effectively.

Clearly, the development and refinement of our understanding of 'self' represents a perpetual and complex challenge for all helpers. After all, we are each a unique product of our biology, personality, life experiences and, as we are currently discovering through epigenetic genealogy, of our distant relatives' experiences (Phillips, 2008). Our unique life experiences impact on us in a myriad of unpredictable and complex ways. For example, the "wounded healer" is a commonly observed therapeutic archetype that suggests that a therapist's own wounds (e.g., adverse life experiences, health and wellbeing challenges, relationship conflicts and breakdowns, grief and trauma) provide a curative benefit for clients (Zerubavel \& Wright, 2012). Consider the personal impact of a traumatic event on one's psychological well-being or perhaps the destructive impact of a negative or abusive relationship with a boss. For many who find themselves having experienced such events, the effective recovery, resolution and post-traumatic growth that can occur through focused therapy can yield increased appreciation for life, more meaningful interpersonal relationships, an increased sense of personal strength, changed priorities and a richer existential existence (Tedeschi \& Calhoun, 2004). When left unprocessed however, these events can lead to problematic adaptations such as post-traumatic stress.

Hence, the importance of psychologists, psychotherapists and counsellors engaging in their own personal therapy, whilst remaining a topic of periodic debate within the profession, has largely been acknowledged as a critical element of a therapist's practice and cannot be underestimated (Corey, 2016; Malikiosi-Loizos, 2013). As the demands and expectations on coaches to practice ethically and within their boundaries of competence and experience, adopting this standard from coaching's allied helping professions becomes increasingly important to the coaching practitioner's personal and professional development and ethical practice.

Generally, people seek out therapy for a myriad of reasons. Whilst many seek therapy to address problem situations such as "...crises, troubles, doubts, difficulties, frustrations or concerns" (Egan \& Reese, 2019, p.10), equally, many seek help to explore and identify opportunities, strengths and continuing self-learning and growth (Egan \& Reese, 2019). Unfortunately for many though, social stigma often serves as a barrier to seeking out mental health treatment (Owen, Thomas \& Rodolfa, 2013). Being aware of and acknowledging the inevitable anxiety, apprehension and subjective stigma that 
may arise when considering the commencement of a therapeutic process is an important first step for coaching practitioners on this development journey and one that can serve as an impetus to embrace the core values of coaching whilst modelling the behaviours we encourage in our clients.

\section{Getting started: Considerations for choosing a process and therapist}

Choosing to enter a growth focused therapeutic relationship is a courageous step and bold declaration of one's personal commitment to the values and virtues coaching espouses. It is because of this that it is vital at this point to consider the key differences in training and education required of therapists more broadly and to clarify the diversity of practitioners operating within the discipline.

Entering a growth focused therapeutic relationship is similar in many ways to the process of entering into a coaching engagement. The relationship between therapist and client, the therapeutic alliance, as we have previously highlighted, is a critical factor in achieving positive developmental outcomes from therapy (Orlinsky, Ronnestad \& Willutski, 2004; Kemp, 2011). Without a strong sense of mutual engagement, trust, rapport, unconditional positive regard, compassion, empathy, and resonance, it may be difficult to realise the full potential of the therapeutic process.

Unlike the title 'Psychologist' and the broader profession of Psychology, counselling and psychotherapy is largely unregulated, is not legislated in many jurisdictions and has fewer controls, assurances and protections for clients as a result. The title of Psychologist is a legally protected title, in most countries, and is restricted in its use to a professional who has been registered or licensed by a statutory authority and has completed both undergraduate and postgraduate training and completed a structured and supervised internship. The titles 'Counsellor' and 'Psychotherapist' have no such restriction and hence, can be used by any individual who wishes to identify themselves this way, regardless of their training, experience or background. For this reason, coaches considering entering a growth focused therapeutic relationship would be wise to seek out an appropriately registered or licensed Psychologist who has specific experience and training in the field of interest to the coach.

Apart from the focused sub-disciplines that distinguish the practice of Psychology more broadly, Psychologists often have individual preferences, skills, qualifications and experience within specific methods and approaches to therapy. A Psychodynamically focused Psychologist, for example, will utilise a 
very different approach to growth and development than a CognitiveBehavioural, Person-Centered, Gestalt, Acceptance and Commitment Therapy (ACT) or Behaviourally focused Psychologist. Hence, in choosing a Psychologist one is also choosing a preferred style of therapy that they believe will align with their growth objectives.

Psychologists are required to only work with clients and methods that they have relevant expertise and experience to work with. This a legislated requirement of their practice. Hence, Psychologists are bound to accurately represent their professional expertise, skill and experience. For many coaches, this constraint will be important in the process of choosing a therapist. For some, a strong background in organisations or business will be important, whilst for others, clinical experience with specific mental health issues or disorders may be more desirable. Matching the Psychologist's experience, training and expertise with the coaches desired growth outcomes is an important part of the selection process.

Finally, cost, structure, session frequency and desired outcomes of the therapeutic engagement, as is the case with any coaching engagement, are important to negotiate and discuss prior to the commencement of the relationship and is the case in all human growth and development processes, the client's openness and readiness to change (grow) are amongst the highest predictors of achieving successful therapeutic outcomes.

\section{Conclusions and recommendations}

The current discussion has explored the historical pathways, challenges and opportunities for the development of coaching practitioners within a rapidly growing and diversifying industry. As the body of knowledge informing coaching psychology and coaching practice has continued to develop, the demands and complexities of coaching continue to broaden and expand. As 'helpers', coaches enjoy a unique and privileged position in our communities, in our organisations and in our broader society. When delivered ethically, professional and competently, coaching interventions enable clients to move more closely to the flourishing end of the mental health continuum and grow as humans.

As coaches continue to seek ways of growing themselves and modelling the commitments and behaviours they expect from their clients, growth focused therapy provides an opportunity for their own deeply transformational development. By engaging in this depth of personal work, coaches are better 
able to calibrate effectively as practitioners and accurately, responsibly, and ethically engage with their clients to best support their movement along the dynamic continuum of mental health and wellbeing. With increasing rates of mental health issues surfacing in our organisations and communities, it is vital that coaches continue to extend and improve their skills, experience, and knowledge in this realm to best support their clients' needs.

\section{References}

Australian Bureau of Statistics. (2018). National Health Survey: First Results 2017-18. ABS.

Bachkirova, T. (2007). Role of coaching psychology in defining boundaries between counselling and coaching. In S. Palmer \& A. Whybrow (eds.), Handbook of Coaching Psychology: A Guide for Practitioners (pp. 351366). Routledge

Bachkirova, T., Jackson, P. \& Clutterbuck, D. (2011). Coaching and mentoring supervision theory and practice. Open University Press McGraw-Hill.

Bernard, J. M., \& Goodyear, R. K. (2009). Fundamentals of Clinical Supervision. (4 ${ }^{\text {th }}$ ed.). Pearson Education, Inc.

Bora, R., Leaning, S., Moores, A. \& Roberts, G. (2010). Life coaching for mental health recovery: The emerging practice of recovery coaching. Advances in Psychiatric Treatment, 16, 459-467.

Corey, G. (2016). Theory and Practice of Counselling and Psychotherapy (10 ed.). Cengage Learning, Inc.

Crowe, T. (2017). Coaching and Psychotherapy. In T. Bachkirova, G. Spence \& D. Drake (eds.), The Sage Handbook of Coaching. Sage.

Egan, G. \& Reese, R.J. (2019). The Skilled Helper: A Problem-Management \& Opportunity-Development Approach to Helping (11 ${ }^{\text {th }}$ ed.). Cengage Learning, Inc.

Goode, W.J. (1960). Encroachment, charlatanism and the emerging profession: Psychology, sociology and medicine. American Sociological Review, $25,902-965$. 
Grant, A.M. (2012). Australian Coaches Views on Coaching Supervision: A Study with Implications for Australian Coach Education, Training and Practice. International Journal of Evidence Based Coaching and Mentoring, 10(2) 17-33.

Gray, D.E. (2007). Towards a systemic model of coaching supervision: Some lessons from psychotherapeutic and counselling models. Australian Psychologist, 42(4), 300-309.

Gray, D.E. (2017). Towards a systemic model of coaching supervision. In T. Bachkirova, G. Spence \& D. Drake (eds), The SAGE Handbook of Coaching. Sage.

Grohol, J. (2020). Psychotherapy. Psych Central. Retrieved on April 10, 2020, from https://psychcentral.com/psychotherapy/

Hawkins, P. (2006). Coaching Supervision: Maximising the Potential of Coaching. CIPD.

Hullinger, A. M. \& DiGirolamo, J. A. (2018). Referring a client to therapy: A set of guidelines. Retrieved from International Coach Federation website: https://coachfederation.org/app/uploads/2018/05/WhitepaperClient-Referral.pdf.

Joseph, S. (2016). A review of research into business coaching supervision. Coaching: An International Journal of Theory, Research and Practice, 9(2), 158-168.

Kemp, T.J. (2008). Coach self-management: The foundation of coaching effectiveness. In D.B. Drake, D. Brennan \& K. Gortz (2008), The Philosophy and Practice of Coaching: Insights and Issues for a New Era. Wiley.

Kemp, T.J. (2009). Is coaching an evolved form of leadership? Building a transdisciplinary framework for exploring the coaching alliance. International Coaching Psychology Review, 4(1), 105-110. 
Kemp, T.J. (2011). Building the coaching alliance: Constructing a lens for understanding the phenomenon of relationship in coaching. In G. Hernez-Broome \& L. A. Boyce (eds). Advancing Executive Coaching: Setting the Course for Successful Leadership Coaching (Chapter 7). Jossey-Bass.

Kemp, T.J. \& Green. S. (2010). Executive Coaching for the Normal "NonClinical" Population: Fact or Fiction. Fourth Australian Evidence-Based Coaching Conference, Sydney University, June.

Kets de Vries, M. (2006). The Leader on the Couch: A clinical approach to changing people and organizations. Jossey-Bass.

Kilburg, R.R. (2004). When shadows fall: Using psychodynamic approaches in executive coaching. Consulting Psychology Journal: Practice and Research. 56(4), 246-268.

Lawrence, P. \& Whyte, A. (2014). What is coaching supervision and is it important? Coaching: An International Journal of Theory, Research and Practice, 7(1), 39-55.

Malikiosi-Loizos, M. (2013). Personal Therapy for Future Therapists: Reflections on a Still Debated Issue. The European Journal of Counselling Psychology, 2(1), 33-50.

Moyes, B. (2009). Literature review of coaching supervision. International Coaching Psychology Review, 4(2), 162-173

Orlinsky, D. E., Ronnestad, M. H., Willutski, U. (2004). Fifty years of psychotherapy process-outcome research: Continuity and change. In M. J. Lambert (Ed.), Handbook of Psychotherapy and Behavior Change (5th Ed.). John Wiley \& Sons.

O’Broin, A. \& Palmer, S. (2009). Co-creating an optimal coaching alliance. International Coaching Psychology Review, 4(2), 184-194.

O’Broin, A. \& Palmer, S. (2010). The Coaching Alliance as a universal concept spanning conceptual approaches. Coaching Psychology International, 3(1), 3-6. 
Owen, J., Thomas, L. \& Rodolfa, E. (2013). Stigma for Seeking Therapy: Self Stigma, Social Stigma, and Therapeutic Processes. The Counselling Psychologist, 41(6), 857-880.

Phillips, T. (2008) The role of methylation in gene expression. Nature Education, 1(1), 116

Spinelli, E. (2010). Coaching and Therapy: Similarities and Divergences. Psychotherapy in Australia, 17(1), 52-58.

Tedeschi, R.G. \& Calhoun, L.G. (2004). Posttraumatic growth: Conceptual foundations and empirical evidence. Psychological Inquiry, 15(1), 1-18.

TNS (2014). State of Workplace Mental Health in Australia. Retrieved: 13/4/20 from https://www.headsup.org.au/docs/default-source/resources/b11270report---tns-the-state-of-mental-health-in-australian-workplaceshr.pdf?sfvrsn $=8$

Whybrow, A., \& Palmer, S. (2006). Taking stock: A survey of coaching psychologists' practices and perspectives. International Coaching Psychology Review, 1, 56-70.

Zerubavel, N. \& Wright, M.O. (2012). The Dilemma of the Wounded Healer. Psychotherapy, 49(4), 482-491.

\author{
Author Contact \\ Dr Travis Kemp \\ Adjunct Professor \\ UniSA Business School \\ University of South Australia \\ Adelaide, SA \\ Australia \\ E: travis@drtrav.com.au
}

